\title{
Prediction of pavement condition based on public perceptions
}

Mabrouk Touahmia*

Department of Civil Engineering, College of Engineering, University of Hail, Hail, Saudi Arabia

\section{ART ICLE INFO}

\section{Article history:}

Received 16 April 2017

Received in revised form

9 July 2017

Accepted 16 July 2017

Keywords:

Pavement

Deterioration

Maintenance

Public perceptions

\begin{abstract}
A B S T R A C T
Accurate prediction of pavement performance is very important for efficient management of road infrastructure. By reducing prediction errors of pavement deterioration, agencies can obtain significant budget savings through timely intervention and accurate planning. The purpose of this research program is to develop a pavement deterioration prediction model based on roadway users' satisfaction and perceptions. This paper presents the results of a satisfaction survey that was designed and distributed to local residents to assess their perceptions regarding urban roads conditions and their maintenance management. The survey data showed a very moderate level of satisfaction from the participants regarding Hail's local pavements. These results provide a clear indication that the performance quality of Hail's local roads are below the satisfactory level and require improvement and a development of a more efficient pavement management system.
\end{abstract}

(C) 2017 The Authors. Published by IASE. This is an open access article under the CC BY-NC-ND license (http://creativecommons.org/licenses/by-nc-nd/4.0/).

\section{Introduction}

Over the past three decades, the road transport network in Saudi Arabia has experienced a remarkable development to keep pace with the fastgrowing population and consequently the large number of vehicles. These roads have normally been designed and constructed to serve for long periods before requiring any major repair or rehabilitation. However, in many cases these pavements experience premature deterioration in forms of roughness; fatigue cracking and surface rutting that affect the performance of the pavement and require enormous funds for maintenance and repair. Pavements performance can be attributed to various factors such as design specifications, construction materials and methods, traffic volumes and loadings, environmental conditions, and maintenance management systems. Bad pavement conditions can increase fuel consumption and travel time and decrease driving comfort (Sinha and Labi, 2007; Ettema et al., 2013). Understanding the effect of these interlocking factors on pavements' performance could be of great help to transport agencies to improve their road construction and maintenance specifications.

Specific Research has shown that public perceptions of road network's serviceability can

\footnotetext{
* Corresponding Author.

Email Address: m.touahmia@uoh.edu.sa

https://doi.org/10.21833/ijaas.2017.08.018

2313-626X/C) 2017 The Authors. Published by IASE.

This is an open access article under the CC BY-NC-ND license

(http://creativecommons.org/licenses/by-nc-nd/4.0/)
}

provide useful information on pavements' performance due to its influence on user's ride quality and safety. Based on such information, road agencies could predict which road should receive the most attention and resources for maintenance improvement to meet users' satisfaction (Ling and $\mathrm{Ng}, 2011$ ). The concept of involving the public in the development of road transportation systems has been the subject of an impressive number of research studies since the 1990s. Haas and Hudson (1996) developed a systematic approach for pavement management using customer-oriented performance measures. Hyman (2004) proposed a pavement maintenance program that incorporates aspects based on customer needs and satisfaction. Flannery et al. (2005) compared drivers' assessments of the performance of urban streets with objective measures of performance. Shafizadeh and Mannering (2006) showed good correlation between physical pavement roughness measures and user perceptions of roughness. Chang et al. (2015) developed an assessment framework of road service quality from users point of view using structural equation modeling. Tehrani et al. (2015) examined the main factors that affect the road roughness based on public perceptions. Hartmann and Ling (2016) stated that road user experience with agencies' road maintenance and traffic management affect the value-in-use of road infrastructure.

Although a great deal of research has been devoted to performance modeling of pavements, a comprehensive model that can predict pavement performance based on drivers perception and 
satisfaction has yet to be developed. This study aims at understanding roadway users' appreciations and perceptions of road serviceability and performance in the region of Hail. This paper presents the results of a satisfaction survey that was distributed to Hail local residents to assess their perceptions regarding urban roads conditions and their maintenance management.

\section{Research methodology}

Mixed method and survey technique was adopted in this study. The methodology employed for data collection was based on both qualitative and quantitative methods. The procedures used for data collection are:

a) a survey-questionnaire was designed and distributed to the local residents in Hail city to assess their perceptions of current status of local roads.

b)a visual condition survey was conducted on a number of representative road segments selected for the purpose of this research.

c) pavement maintenance data was acquired from the local department of transport database and from a number of contractors.

The survey was distributed to the local residents of Hail city to assess their perceptions on the local roads and to collect the necessary information related to the condition of pavements and their maintenance process. The survey was composed of five sections and contained 24 items of different type such as, Likert-scale type, multiple answers, single answer, and open questions (Table 1).

The first section of the survey included general information on the participants and their driving experiences.

The second section addressed public perceptions of various pavements' aspects such as surface condition, surface drainage, pavement marking and signs, ride comfort, pavement safety and maintenance activities. In this section, participants were asked to evaluate individual pavement characteristics using a 5-point rating scale (VS: very satisfied; S: satisfied; N: neutral; D: dissatisfied; VD: very dissatisfied).

In the third section participants were asked to assess the maintenance activities such as the quality of maintenance works and the maintenance response time.

In the fourth section, respondents were asked to rate their overall satisfaction with the local roads and to rank their reasons for dissatisfaction in a 5point rating scale (VG: very good; G: good; A: average; P: poor; VP: very poor).

The fifth was concerned with the causes of road users' dissatisfaction. In this section participants were asked to rank from 1 to 6 their reasons for dissatisfaction with local roads. In the last section the participants were asked to identify the different types of pavement defects that they usually encountered using a 5-point rating scale (Al: always; Us: usually; Of: often; So: sometimes; Ne: never).

Table 1: Participants' perceptions of pavement aspects With reference to Hail's local roads, how satisfied or dissatisfied are you with the following pavement aspects?

$$
\begin{gathered}
\text { Item } \\
\text { Surface condition } \\
\text { Surface drainage } \\
\text { Marking and signs } \\
\text { Ride comfort } \\
\text { Pavement safety }
\end{gathered}
$$

With reference to Hail's local roads, how satisfied or dissatisfied are you with the following pavement maintenance attributes? $\begin{array}{cccccc}\text { Item } & \text { VS } & \text { S } & \text { N } & \text { D } & \text { VD }\end{array}$ Quality of maintenance works

Maintenance response time

Overall, with reference to Hail's local roads, how would rate the following?

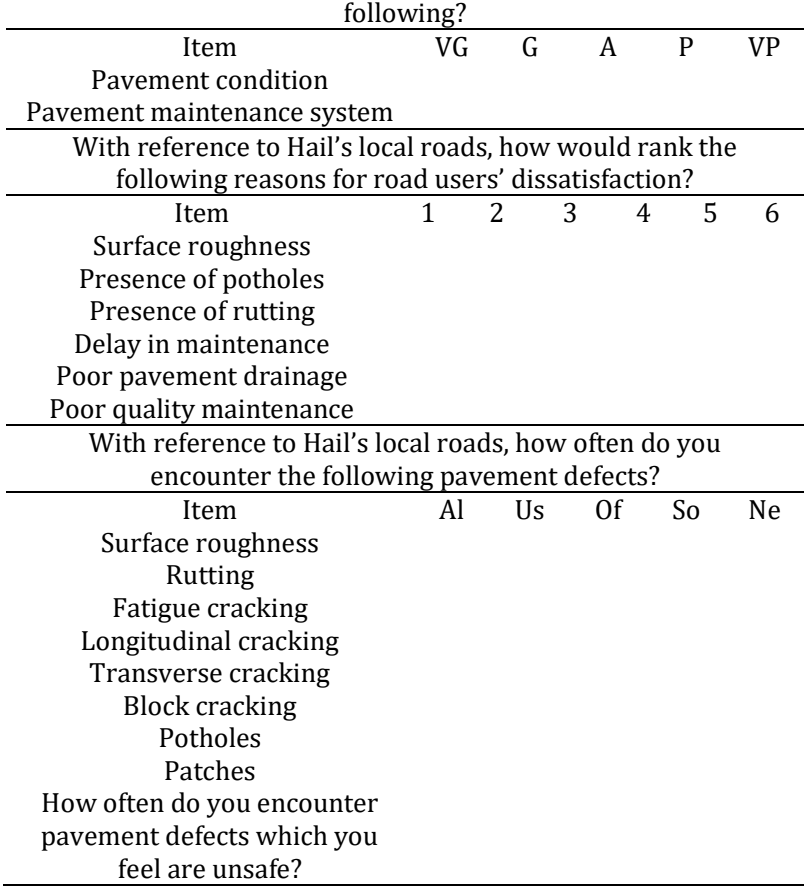

Throughout the survey, respondents were asked to base their answers on their experiences of using local roads only. The survey allows obtaining public perceptions and priorities with regard to the local road network development and to identify the most types of pavement defects that encountered by road users.

It also provides an assessment of pavements network performance and maintenance management system efficiency.

\section{Data analysis}

More than 500 questionnaires were distributed randomly to a sample of people living in Hail. The total number of completed and returned questionnaires was 162 giving a rate of $32.4 \%$. The analysis of the collected Data was performed with the statistical package Minitab software and involved the use of appropriate descriptive statistical techniques.

In general, the respondents are mainly men falling within the age group of 19 to 59 years, welleducated and having a good driving experience. 
Nearly 70 percent of the participants have a college or university level and more than 90 percent of them have a driving experience of more than one year as detailed in Tables 2. The large number of educated participants may be attributed, in part, to the greater involvement of students from Hail University to this study. Surprisingly, fewer individuals over the age of 60 participated in the study.

Table 2: Respondents' personnel information

\begin{tabular}{cccccc}
\hline $\begin{array}{c}\text { Age } \\
\text { Group }\end{array}$ & $\%$ & $\begin{array}{c}\text { Education } \\
\text { Level }\end{array}$ & $\%$ & $\begin{array}{c}\text { Driving } \\
\text { Experience }\end{array}$ & $\%$ \\
\hline $19-29$ & 52.47 & University & 46.30 & $<1$ & 7.41 \\
$30-39$ & 15.43 & College & 22.22 & $1-5$ & 40.12 \\
$40-49$ & 16.67 & Secondary & 17.28 & $6-10$ & 21.60 \\
$50-59$ & 12.96 & Elementary & 11.73 & $11-20$ & 18.52 \\
$60-69$ & 2.47 & Other & 2.47 & $>20$ & 12.35 \\
\hline
\end{tabular}

Examination of the data showed a moderate level of satisfaction from the participants with local pavements. Fig. 1 shows the respective levels of public satisfaction with each of the identified aspects of local pavements. As can be seen, all pavements' attributes scored below-average ratings of satisfaction, indicating that they require improvement actions. It is interesting to note that the surface condition received the lowest percentage of satisfaction $(11 \%)$, which tends to confirm the respondents desire and priority for the improvement of pavement.

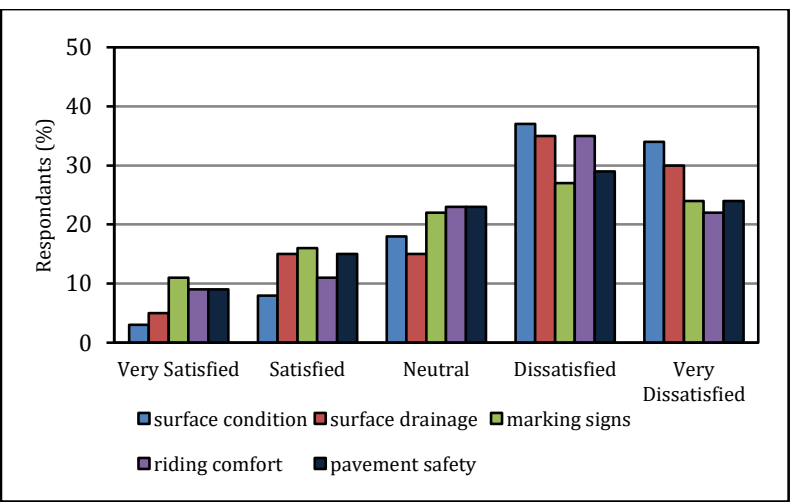

Fig. 1: Respondents perception of identified pavement aspects

The maintenance services also received a low rating of perception from the respondents. As can be seen in Fig. 2, only $22 \%$ of respondents reported they were satisfied with the quality of maintenance works and more than half of the participants (57\%) are not satisfied. The maintenance response time received also a lower satisfaction rating (19\%) as illustrated in Fig. 2.

The overall assessment of the pavement condition is shown if Fig. 3. As can be seen, a moderate level of satisfaction from the participants with local pavements is noted. Only one-fifth of the respondents reported they were satisfied with local pavement condition and more than $50 \%$ are not satisfied.

This result provides a clear indication that the performance quality of Hail's local roads is below the satisfactory level and this requires improvement.
When asked about the overall rating of the maintenance management system, about $54 \%$ of respondents rated it below the average as shown in Fig. 3. This outcome tends to confirm the necessity for developing a more efficient pavement management system for Hail's local roads.

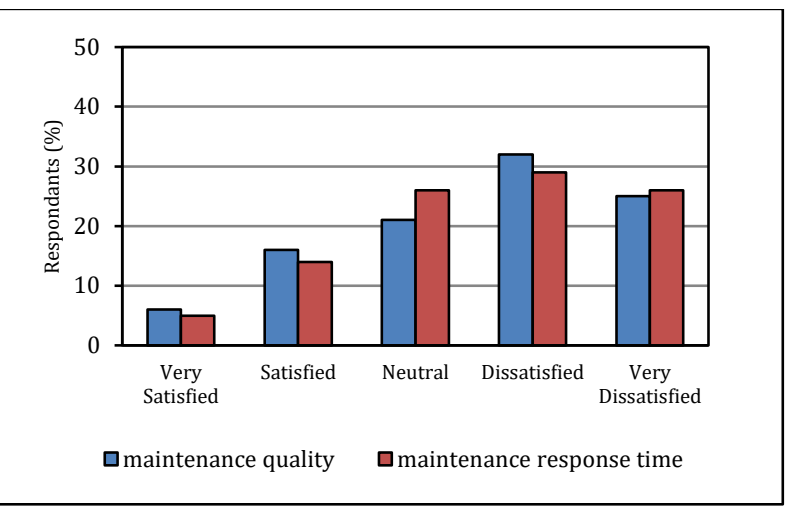

Fig. 2: Respondents perception of the maintenance activities

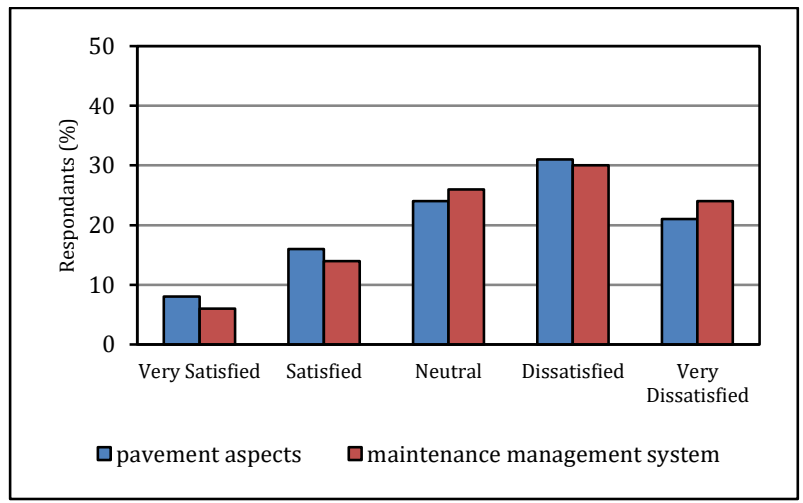

Fig. 3: Overall rating of local roads

Fig. 4 presents the reasons for road users' dissatisfaction. As can be seen, $27 \%$ of participants cited the pavement surface roughness as their main reason for dissatisfaction, followed by the maintenance quality and the pavement poor drainage at $19 \%$ and $17 \%$ of responses respectively.

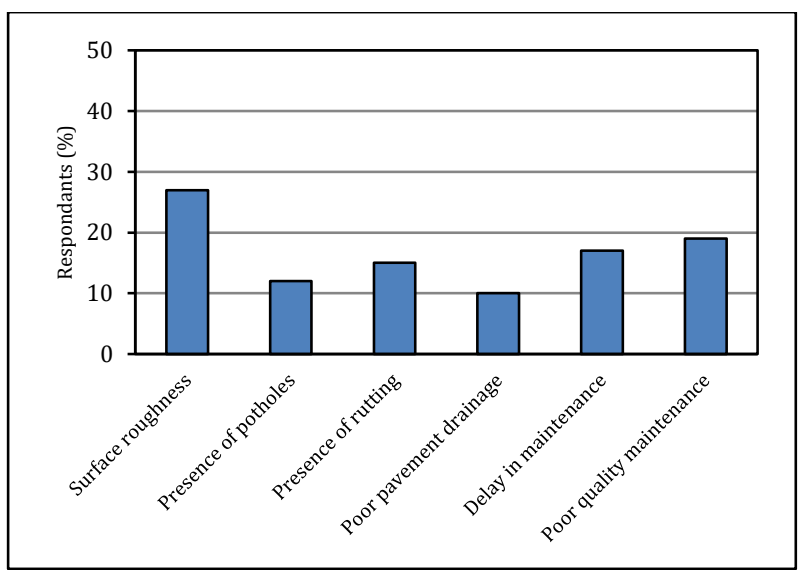

Fig. 4: Road-users reasons for dissatisfaction

One of the fundamental questions underlying this research was how often do you encounter pavement defects which you feel are unsafe? Nearly all respondents (93\%) said they "always" or "usually" 
encounter pavement defects which they felt were unsafe as shown in Fig. 5.

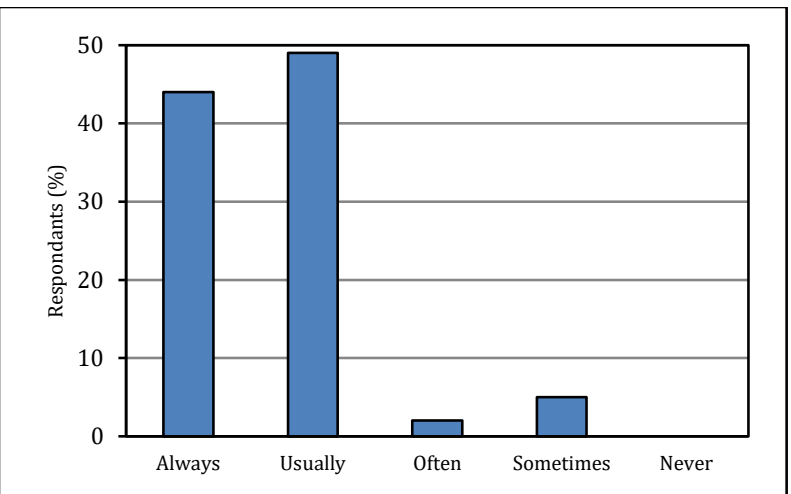

Fig. 5: Respondents encountering unsafe pavement defects

\section{Conclusion}

This paper presents the results of a satisfaction survey that was designed and distributed to local residents to assess their attitudes and perceptions regarding urban roads conditions and their maintenance management. The results of this study have provided the following conclusions:

- The survey data showed a very moderate level of satisfaction from the participants with Hail's local pavements. All pavements' attributes scored below-average ratings of satisfaction, indicating that they require improvement actions.

- The surface condition received the lowest percentage of satisfaction, which tends to confirm the respondents desire and priority for the improvement of pavement.

- Pavement maintenance services received a low rating of perception from the respondents. Most of the respondents reported they were not satisfied with the quality of maintenance works and with the maintenance response time.

- In general, the obtained results provide a clear indication that the performance quality of Hail's local roads are below the satisfactory level and require improvement and a development of a more efficient pavement management system.

\section{Acknowledgment}

The research reported herein was funded by the Deanship of Scientific Research at the University of Hail, Saudi Arabia, under the contract (E-11-AE). The authors would like to express their deepest gratitude to the Deanship of Scientific Research and to the College of Engineering at the University of Hail for providing necessary support to conducting this research.

\section{References}

Chang JR, Liu PJ, and Chen GC (2015). The service quality of roads in taiwan from the point of view of road users and drivers. Journal of Marine Science and Technology, 23(3): 344-352.

Ettema D, Gärling T, Olsson LE, Friman M, and Moerdijk S (2013). The road to happiness: Measuring Dutch car drivers' satisfaction with travel. Transport Policy, 27: 171-178.

Flannery A, Wochinger K, and Martin A (2005). Driver assessment of service quality on urban streets. Transportation Research Record: Journal of the Transportation Research Board, 1920: 25-31.

Haas R and Hudson WR (1996). Defining and serving clients for pavements. Transportation Research Record: Journal of the Transportation Research Board, 1524: 1-9.

Hartmann A and Ling FYY (2016).Value creation of road infrastructure networks: A structural equation approach. Journal of Traffic and Transportation Engineering, 3(1): 2836.

Hyman WA (2004). Guide for customer-driven benchmarking of maintenance activities (NCHRP Report 511). Transportation Research Board, Washington, USA.

Ling FYY and Ng WT (2011). Boosting performance of road infrastructure: A case study based on motorist satisfaction in Singapore. Built Environment Project and Asset Management, 1(2): 211-225.

Shafizadeh K and Mannering F (2006). Statistical modeling of user perceptions of infrastructure condition: Application to the case of highway roughness. Journal of Transportation Engineering, 132(2): 133-140.

Sinha KC and Labi S (2007). Transportation decision making: principles of project evaluation and programming. John Wiley \& Sons, Inc., Hoboken, USA.

Tehrani SS, Falls LC, and Mesher D (2015). Road users' perception of roughness and the corresponding IRI threshold values. Canadian Journal of Civil Engineering, 42(4): 233-240. 